\title{
Radiosensitization of human lung cancer cells by the novel purine-scaffold Hsp90 inhibitor, PU-H71
}

\author{
TATSUYA SEGAWA $^{1}$, YOSHIHIRO FUJII ${ }^{1}$, AYA TANAKA ${ }^{1}$, SHIN-ICHI BANDO $^{2}$, \\ RYUICHI OKAYASU ${ }^{3}$, KEN OHNISHI ${ }^{2}$ and NOBUO KUBOTA ${ }^{1}$
}

\begin{abstract}
Departments of ${ }^{1}$ Radiological Sciences and ${ }^{2}$ Biology, Center for Humanity and Arts, Ibaraki Prefectural University of Health Sciences, Ami-machi, Inashiki-gun, Ibaraki 300-0394; ${ }^{3}$ Heavy-ion Radiobiology Group, Research Center for Charged Particle Therapy, National Institute of Radiological Sciences, Inage-ku, Chiba 263-8555, Japan
\end{abstract}

Received August 30, 2013; Accepted December 13, 2013

DOI: $10.3892 /$ ijmm.2013.1594

\begin{abstract}
The molecular chaperone heat shock protein 90 (Hsp90) is involved in the maturation and stabilization of a wide range of oncogenic client proteins for oncogenesis and malignant cell proliferation, which renders this protein a promising target in the development of cancer therapeutics. PU-H71 is a purine-scaffold Hsp90 inhibitor with less toxicity in normal cells than in cancer cells. In this study, we examined the in vitro radiosensitizing activity and molecular mechanisms of action of PU-H71 in human lung cancer cell lines. PU-H71 enhanced the sensitivity of the SQ-5 and A549 cancer cells to radiation. When the cancer cells were pre-treated with PU-H71, the repair of DNA double-strand breaks (DSBs) was markedly inhibited after irradiation compared with the cells that were not pre-treated with PU-H71, as evaluated by counting the foci of phosphorylated histone $\mathrm{H} 2 \mathrm{AX}(\gamma-\mathrm{H} 2 \mathrm{AX})$. We further demonstrated that post-irradiation, PU-H71 inhibited Rad51 foci formation, a critical protein for the homologous recombination pathway of DNA DSB repair. These data indicate that targeting Hsp90 with PU-H71 may be novel therapeutic strategy for radioresistant carcinomas.
\end{abstract}

\section{Introduction}

The molecular chaperone heat shock protein 90 (Hsp90) was initially identified as one of the highly conserved heat shock proteins $(1,2)$. The Hsp90 proteins are ubiquitous molecular chaperones that have important functions in protein folding and in renaturation $(3,4)$. They also play a key role in the stability and function of a number of client proteins. To date, $>200$ client proteins are known to be regulated by Hsp90, including

Correspondence to: Dr Nobuo Kubota, Department of Radiological Sciences, Ibaraki Prefectural University of Health Sciences, 4669-2 Ami, Ami-machi, Inashiki-gun, Ibaraki 300-0394, Japan

E-mail: sxmtq653@ybb.ne.jp

Key words: heat shock protein 90 inhibitor, PU-H71, radiosensitization, DNA repair inhibition mutated and oncogenic regulatory and signaling proteins (ErbB2, Akt, Raf-1, mutated p53), cell cycle regulators (Cdk4, CdK6) and steroid receptors (5). A number of these proteins are mutated and/or overexpressed in cancers, indicating that the client proteins are directly associated with oncogenesis upon Hsp90 machinery. For this reason, Hsp90 has emerged as a promising target in the development of cancer therapeutics.

ATP-competitive Hsp90 inhibitors, including the benzoquinone ansamycin, 17-allylamino-17-demethoxygeldanamycin (17-AAG) and its derivatives, 17-dimethylaminoethylamino17-demethoxygeldanamycin (17-DMAG) and IPI-504, have been developed as antitumor agents (6). We, as well as others have previously reported that the benzoquinone ansamycins, geldanamycin and 17-AAG, sensitize tumor cells, but not normal cells, to radiation (7-10). The mechanisms responsible for the enhancement of the radiation response in tumor cells have been suggested to induce apoptosis by inhibiting cell survival signals. We have also previously demonstrated that 17-AAG inhibits the repair of radiation-induced DNA double-strand breaks (DSBs) in tumor cell lines, but not in normal cells (11).

The ansamycin, 17-AAG, was the first Hsp90 inhibitor to enter clinical trials. In a phase I trial of 17-AAG in patients with advanced cancer, early clinical results revealed delayed hepatotoxicity with a twice-weekly continuous dosing schedule (12). In addition, its limited solubility and stability have led to the development of derivative compounds, such as 17-DMAG and IPI-504, which have been investigated for the treatment of different malignancies. However, side-effects remain a concern with these newer ansamycins (13). These results prompted the development of a non-ansamycin Hsp90 inhibitor. Chiosis et al designed Hsp90 inhibitors using purine as a scaffold, of which 8-(6-indozenzo[d][1,3]dioxol-5-ylthio)9-(3-(isopropylamino)propyl)-9H-purine-6-amine (PU-H71) is the most potent (14). PU-H71 has shown anticancer activity in pre-clinical trials on triple-negative breast cancer (15), lymphoma (16) and hepatocellular carcinoma (17), suggesting that it is a promising drug for the treatment of cancer.

In this study, we demonstrate that PU-H71 sensitizes the human lung cancer cell lines, SQ-5 and A549, to radiation. As shown by our results, PU-H71 inhibited the repair of radiation-induced DSBs in both cancer cell lines, and significantly disturbed the homologous recombination (HR) 
pathway, one of the DSB repair pathways (18). Therefore, our data demonstrate that the inhibition of Hsp90 by PU-H71 represents an effective method to enhance the sensitivity of cancer cells to radiotherapy.

\section{Materials and methods}

Cell lines, culture and drugs. The human lung cancer cell lines, SQ-5 and A549, and the normal fibroblast cell line, HFL-III, were used in this study. The cells were cultured in $\alpha$-MEM supplemented with $10 \%$ fetal calf serum, $20 \mathrm{mM}$ 4-(2-hydroxyethyl)piperazine-1-ethanesulfonic acid (HEPES), $8 \mathrm{mM} \mathrm{NaHCO}, 50 \mathrm{U} / \mathrm{ml}$ penicillin and $50 \mu \mathrm{g} / \mathrm{ml}$ streptomycin. The cells were cultured in a humidified incubator at $37^{\circ} \mathrm{C}$ with a mixture of $98 \%$ air and $2 \% \mathrm{CO}_{2}$. PU-H71 was purchased from Sigma-Aldrich (St. Louis, MO, USA), stored in aliquots at $-20^{\circ} \mathrm{C}$ at $2 \mathrm{mM}$ solution in DMSO, and diluted in $\alpha$-MEM immediately prior to use.

Irradiation. The cells were irradiated at room temperature with $10 \mathrm{MV}$ X-rays from a linear accelerator (EXL-15SP, Mitsubishi Electric, Tokyo, Japan) at a dose rate of $4 \mathrm{~Gy} /$ min. Doses were measured using an Innax Dosemaster 2590 (NE Technologies, Atlanta, GA, USA).

Cell survival. Cell survival was measured by a colony formation assay, as previously described (8). Actively growing cells in $24 \mathrm{~cm}^{2}$ flasks were incubated with $1 \mu \mathrm{M}$ PU-H71 for $16 \mathrm{~h}$ at $37^{\circ} \mathrm{C}$, irradiated with X-rays and incubated in the presence of the drug for a further $8 \mathrm{~h}$. Following treatment with PU-H71 for $24 \mathrm{~h}$, the cells were washed with Dulbecco's phosphatebuffered saline (PBS) and dispersed with $0.05 \%$ trypsin containing $0.02 \%$ EDTA, counted, diluted and seeded in 60-mm or 100-mm dishes at various cell densities. Following 12-14 days of incubation in a $\mathrm{CO}_{2}$ incubator, the colonies were stained with crystal violet dissolved in $20 \%$ methanol. Colonies of $>50$ cells were counted as survivors.

Immunofluorescence. Immunofluorescence was performed as previously described (19). Briefly, the cells were grown on glass slides placed in 100-mm dishes and exposed to PU-H71 at $1 \mu \mathrm{M}$ or DMSO for $16 \mathrm{~h}$, irradiated with X-rays of $5 \mathrm{~Gy}$, and incubated in the presence of the drug for a further $8 \mathrm{~h}$ at $37^{\circ} \mathrm{C}$. The medium was then removed and replaced with fresh drug-free medium. At various time points until $24 \mathrm{~h}$ after X-ray irradiation, the medium was removed, and the cells were fixed with cold methanol for $20 \mathrm{~min}$ followed by acetone for 5-10 sec, air-dried and blocked with $10 \%$ bovine serum albumin (BSA) in PBS. The cells were then washed twice with PBS and incubated with primary antibodies for $1 \mathrm{~h}$. The primary antibody used for immunostaining was anti-phospho-H2AX (Ser139) (Merck Millipore, Darmstadt, Germany) and Rad51 (GeneTex, Inc. Irvine, CA, USA). The cells were again washed twice with PBS and incubated with the secondary antibody (Alexa Fluor 488 goat anti-mouse IgG; Life Technologies, Carlsbad, CA, USA) in PBS with $1 \%$ BSA, and washed twice again. Subsequently, the cells were incubated with 4',6-diamidino-2-phenylindole (DAPI) in PBS for $5 \mathrm{~min}$ and again washed twice. Cover glasses were mounted and fluorescence images were captured using a fluorescence microscope (Olympus, Tokyo, Japan). The foci of $\gamma$-H2AX and Rad51 were counted in at least 50 cells.

Immunoblotting. The cells were exposed to PU-H71 or DMSO for $16 \mathrm{~h}$, irradiated with 5 Gy X-rays, and incubated in the presence of the drug for a further $8 \mathrm{~h}$. The cells were washed with ice-cold PBS, collected and pelleted by centrifugation. The cells were lysed in lysis buffer (Cell Signaling Technology, Danvers, MA, USA) containing $1 \mathrm{mM}$ phenylmethylsulfonyl fluoride (PMSF) for $30 \mathrm{~min}$ on ice. The cell lysates were centrifuged at $15,000 \mathrm{rpm}$ for $10 \mathrm{~min}$ at $4^{\circ} \mathrm{C}$ and the supernatant was recovered. The protein concentration was measured using a BCA protein assay kit (Thermo Scientific, Rockford, IL, USA). Lysates of $20 \mu \mathrm{g}$ protein were boiled in sample buffer and separated by electrophoresis on $7.5 \%$ polyacrylamide gel, and electrotransferred onto polyvinylidene difluoride (PVDF) membranes using a semi-dry transfer system. The membranes were blocked in 5\% non-fat milk for $1 \mathrm{~h}$ at room temperature, and incubated overnight at $4^{\circ} \mathrm{C}$ with primary antibody. Then, membranes were washed 3 times with PBS-T and incubated with a secondary antibody conjugated to horseradish peroxidase for $1 \mathrm{~h}$. After washing 3 times, immunoblots were visualized by an enhanced chemiluminescence (ECL) detection system (GE Healthcare, Fairfield, CT, USA).

Detection of apoptosis. The induction of apoptosis was measured by detecting the number of apoptotic bodies (8). The cells were incubated with PU-H71 at $1 \mu \mathrm{M}$ or DMSO for $16 \mathrm{~h}$, irradiated with 6 Gy X-rays, and then incubated in the presence of the drug for a further $8 \mathrm{~h}$. The medium was removed and replaced with fresh drug-free medium. Twenty-four hours after X-ray irradiation, both attached and floating cells were collected by trypsinization and centrifugation, resuspended in a fixed solution containing 3\% paraformaldehyde in PBS and stained with DAPI. The cells were placed on microscope slides and covered with glass coverslips. The cells were then photographed using a fluorescence microscope, and the numbers of apoptotic and non-apoptotic cells were counted.

\section{Results}

PU-H71 inhibits the proliferation of cancer cells. The effects of PU-H71 (Fig. 1A) on the growth of lung cancer and normal fibroblasts are shown in Fig. 1B. Actively growing cells were treated with PU-H71 at various concentrations for $24 \mathrm{~h}$. PU-H71 inhibited the growth of cancer cells more effectively than that of normal cells.

PU-H71 sensitizes cancer cells to radiation. The ability of PU-H71 to enhance the sensitivity of the SQ-5, A549 and HFL-III cells to radiation in vitro was assessed by a clonogenic assay (Fig. 2). Cell survival curves for SQ-5, A549 and HFL-III cells after X-irradiation in the presence or absence of PU-H71 were constructed. Cells were exposed to PU-H71 at $1 \mu \mathrm{M}$ for $16 \mathrm{~h}$, irradiated with X-rays and incubated for a further $8 \mathrm{~h}$ in the presence of the drug. Each radiation survival curve after a combination of X-rays and PU-H71 was corrected for drug cytotoxicity. Irradiation in combination with PU-H71 had a strong radiosensitizing effect on the SQ-5 cells. In the A549 cells, a moderate sensitizing effect of PU-H71 was observed. 
A

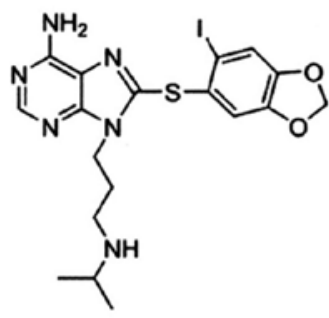

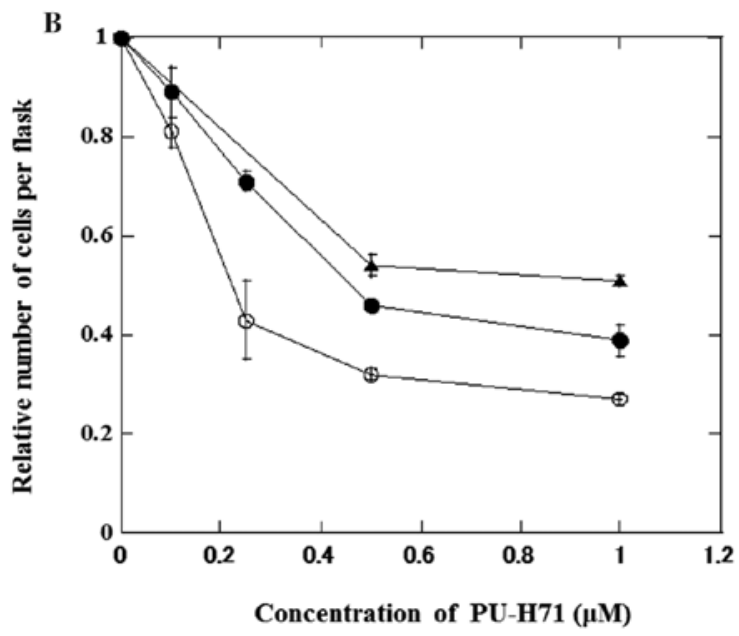

Figure 1. (A) Chemical structure of PU-H71 and (B) its effects on the growth of SQ-5 (॰), A549 (•) and HFL-III cells (₫). Cells were plated in flasks, incubated overnight, and exposed to various concentrations of PU-H71 for $24 \mathrm{~h}$, and cell growth was measured by cell counting. Error bars represent the means \pm SEM of 3 independent experiments.
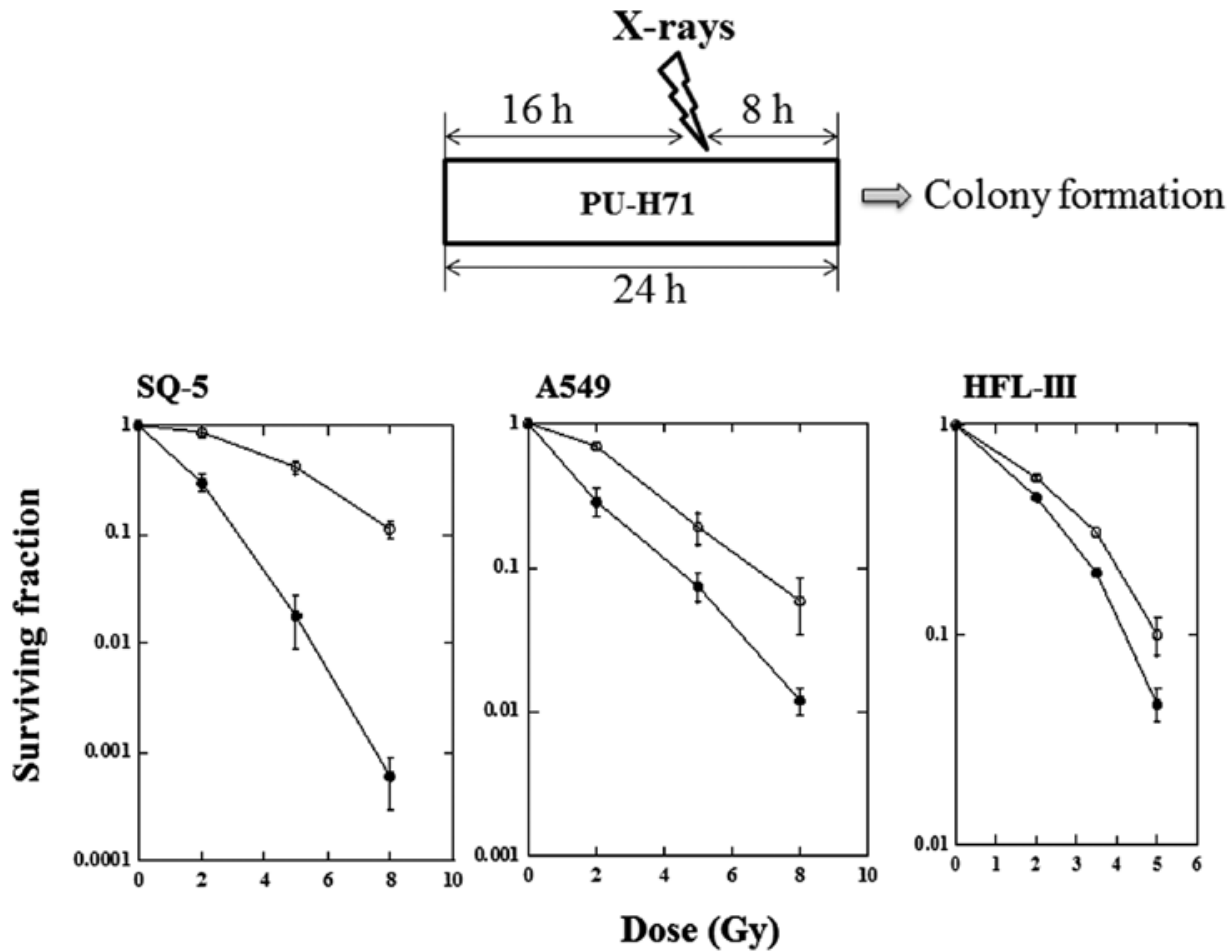

Figure 2. Effects of PU-H71 on the survival of SQ-5, A549 and HFL-III cells following exposure to X-rays. The cells were incubated with PU-H71 at $1 \mu$ M or DMSO for $16 \mathrm{~h}$ at $37^{\circ} \mathrm{C}$, exposed to various doses of X-rays, and incubated for a further $8 \mathrm{~h}$ in the presence of the drug. Cell survival was determined by colony formation assay. Error bars represent the means \pm SEM of 3 independent experiments..

The HFL-III cells showed a lesser degree of radiosensitization. The radiosensitivity enhancement ratios at a survival rate of $10 \%$ were $2.5,1.5$ and 1.2 in the SQ-5, A549 and HFL-III cells, respectively.

PU-H71 inhibits radiation-induced DNA DSBs in cancer cells. With respect to radiation-induced cell death, DSBs are believed to be the most severe damage caused to cells and, if not repaired, can lead to genomic instability and cell death. To elucidate the molecular mechanisms behind the radiosensitizing effects of PU-H71 on cancer cells, we measured the repair of DSBs by evaluating the foci of phosphorylated histone $\mathrm{H} 2 \mathrm{AX}(\gamma-\mathrm{H} 2 \mathrm{AX})$, an indicator of DSBs. The results are presented in Fig. 3. In the SQ-5 cells, the number of foci at $30 \mathrm{~min}$ after X-rays of $5 \mathrm{~Gy}$ alone was almost identical to that following the combination of PU-H71 and X-rays. In the A549 cells, there were slightly more foci at $30 \mathrm{~min}$ following the combination of PU-H71 and X-rays compared with X-rays alone. In both cell lines, the number of foci in the cells exposed to both PU-H71 and X-rays was significantly higher compared with X-rays alone at 8 and $24 \mathrm{~h}$, indicating that PU-H71 inhibits the repair of DSBs in cancer cells. Our observations 

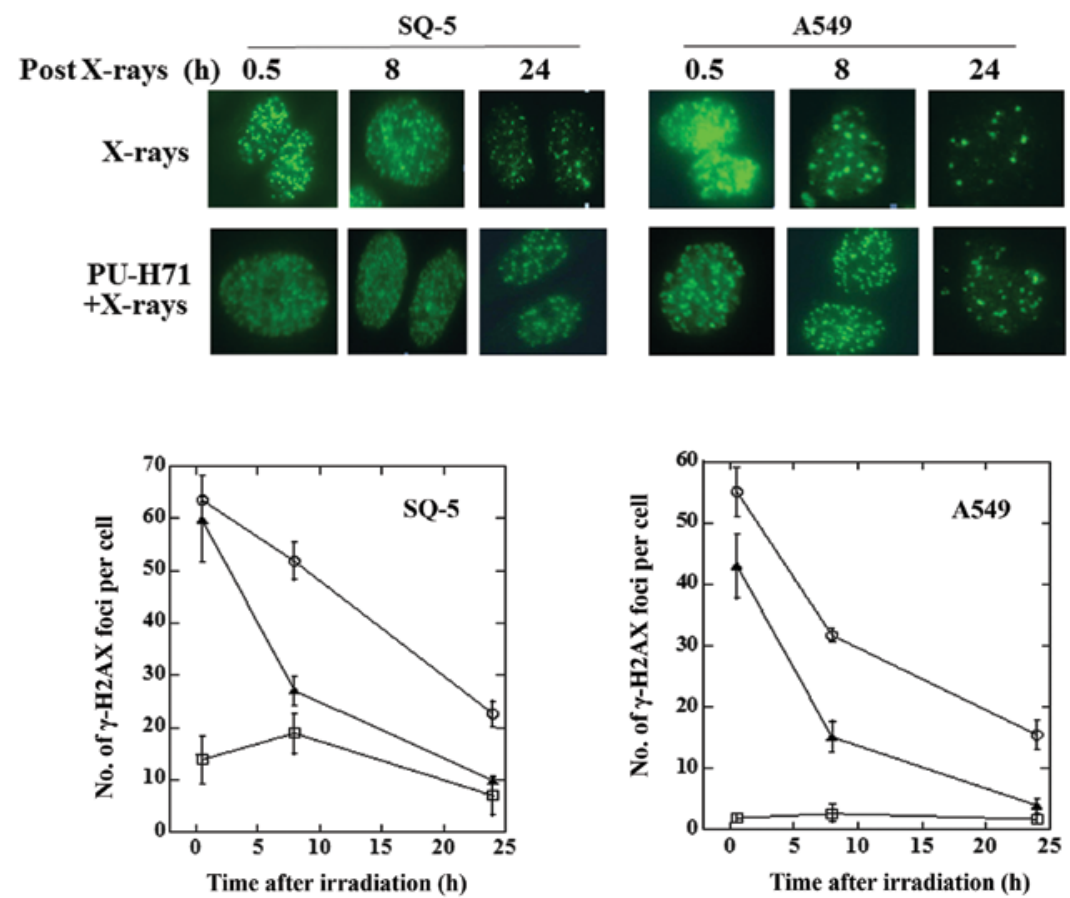

Figure 3. Repair kinetics of radiation-induced DNA double strand breaks (DSBs) in SQ-5 and A549 cells. Cells were pre-treated with either $1.0 \mu \mathrm{M}$ PU-H71 or DMSO for $16 \mathrm{~h}$, irradiated with $5 \mathrm{~Gy}$ of X-rays, then incubated in the presence of the drug for a further $8 \mathrm{~h}$. The medium was then removed and replaced with fresh drug-free medium. Foci formations of $\gamma$-H2AX (Ser139) in SQ-5 and A549 cells irradiated with 5 Gy X-rays were counted. Nuclei were stained with DAPI. Error bars represent the means \pm SEM of 3 independent experiments..

A

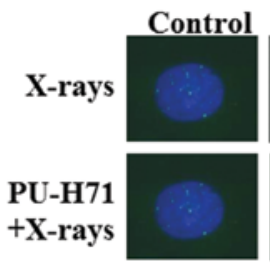

B

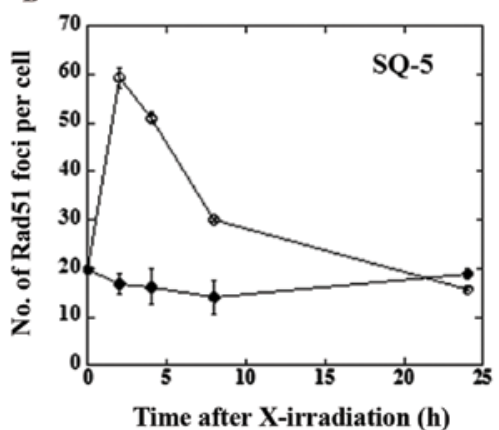

SQ-5
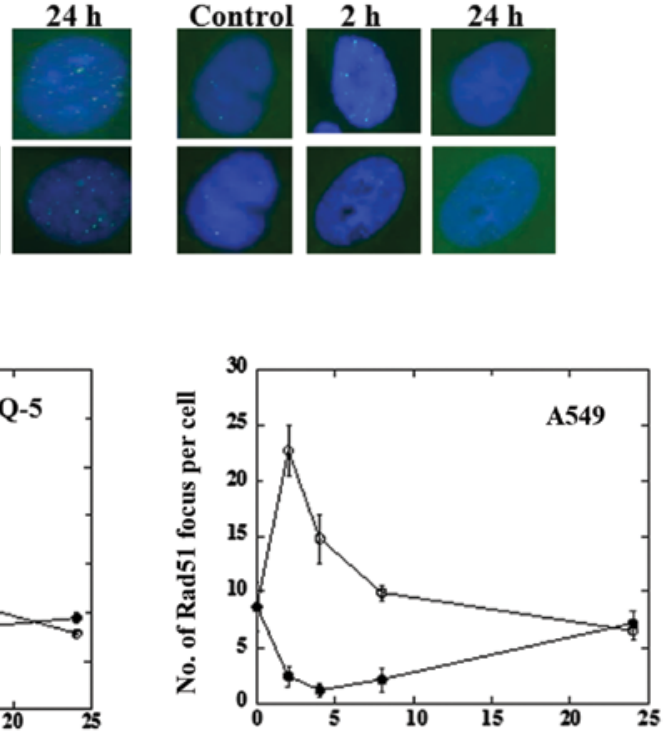

Time after X-irradiation (h)
A549

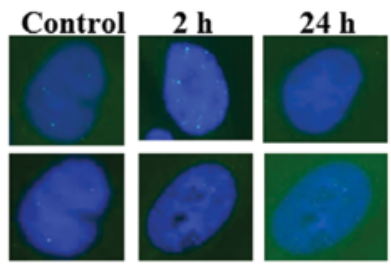

C

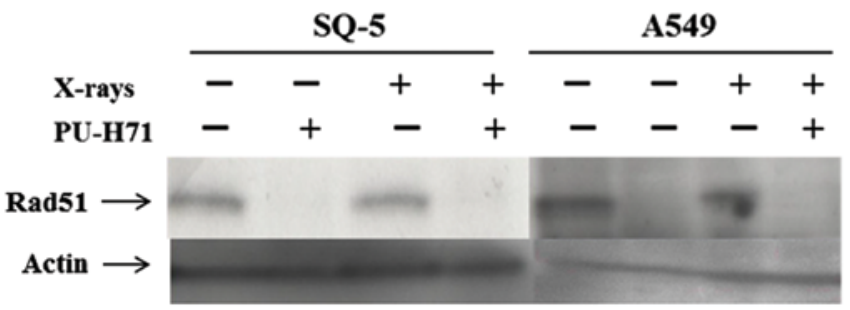

Figure 4. Effects of PU-H71 on Rad51 protein. (A) Representative images of foci formation corresponding to Rad51 in SQ-5 and A549 cells. (B) Kinetics of radiation-induced Rad51 foci formation after X-rays with or without PU-H71 in SQ-5 and A549 cells. Treatment with PU-H71 and X-ray irradiation is the same as described in Fig. 3. Error bars represent the means \pm SEM of 3 independent experiments. (C) Effects of PU-H71 and X-rays on the expression of Rad51 protein. Cells were treated with PU-H71 at $1.0 \mu \mathrm{M}$ for $24 \mathrm{~h}$, X-rays of $5 \mathrm{~Gy}$, or both. Rad51 expression was determined by immunoblotting. $\beta$-actin was used as a loading control 
A

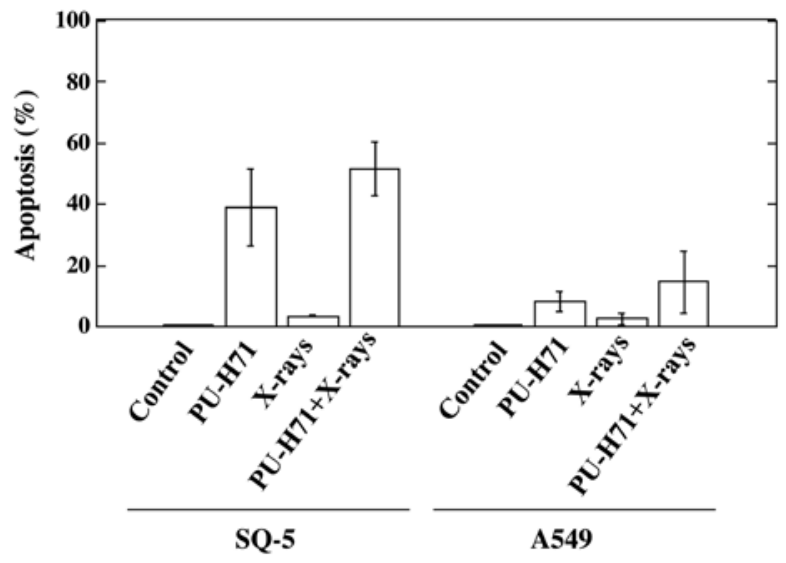

B

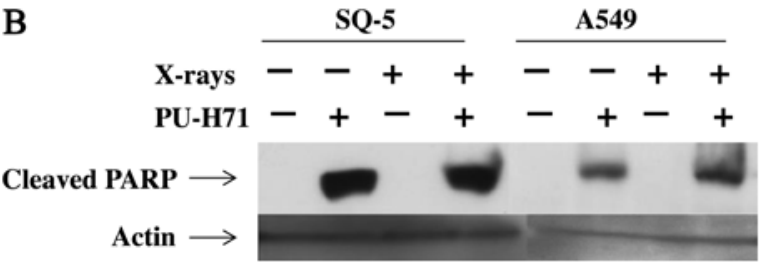

Figure 5. PU-H71 induces tumor cell apoptosis. (A) Apoptosis in SQ-5 and A549 cells exposed to X-rays of 6 Gy with or without PU-H71. Apoptotic cells were measured $24 \mathrm{~h}$ after $\mathrm{X}$-irradiation. Error bars represent the means $\pm \mathrm{SEM}$ of 3 independent experiments. (B) Cleavage of PARP following exposure to X-rays with or without PU-H71. Cells were harvested $24 \mathrm{~h}$ after 6 Gy irradiation and lysed. For the detection of PARP, lysates were analyzed by western blot analysis using an anti-cleaved PARP antibody. $\beta$-actin was used as a loading control.

suggest that PU-H71 radiosensitizes cancer cells by inhibiting the repair of radiation-induced DSBs.

PU-H71 inhibits radiation-induced Rad51 foci formation in tumor cells. In response to ionizing radiation, the Rad51 protein, which is essential for the HR pathway of DSB repair, relocalizes within the nucleus to form distinct foci that can be visualized by fluorescence microscopy and that are thought to represent sites where DSB repair reactions occur (20). To investigate the mechanisms by which PU-H71 inhibits the repair of radiation-induced DSBs, we examined its effects at $1 \mu \mathrm{M}$ on radiation-induced Rad51 foci formation in SQ-5 and A549 cells (Fig. 4A and B). A distinct difference was observed between the effect of X-rays alone and the combination of PU-H71 treatment and radiation in the cancer cell lines. Upon treatment with X-ray irradiation alone, the formation of Rad51 nuclear foci was observed at $2 \mathrm{~h}$, and then gradually decreased. However, in the presence of PU-H71, there was little Rad51 foci formation in response to radiation. We then investigated the expression levels of the Rad51 protein in both cell lines treated with PU-H71. Rad51 protein levels were decreased following treatment with PU-H71 at $1 \mu \mathrm{M}$ for $24 \mathrm{~h}$ (Fig. 4C). These results reveal that PU-H71 exerts a marked effect on the HR pathway.

PU-H71 induces apoptosis in cancer cells. The apoptosisinducing effect of PU-H71 was examined using DAPI staining. Treatment with X-rays alone did not induce apoptosis in the
SQ-5 and A549 cells. The combination of PU-H71 and X-rays induced a marked increase in the number of apoptotic SQ-5 cells and a slight increase in the number of apoptotic A549 cells (Fig. 5A). We then examined the cleavage of PARP by western blot analysis using cleaved PARP antibody. Similar to apoptosis induction, PU-H71 treatment with or without X-rays induced the cleavage of PARP protein in both cells; however, this was not observed with X-rays alone (Fig. 5B), indicating that caspase- 3 is activated following treatment with PU-H71 in both cell lines.

\section{Discussion}

In clinical radiotherapy, tumor radioresistance is one of the causes of local failure after radiotherapy. The development of drugs that enhance the sensitivity of tumor cells to radiation is thus of great importance. Although a number of studies have focused on radiosensitizers, no truly clinically effective treatments have been developed. Several groups have shown that Hsp90 inhibitors enhance the radiation sensitivity of human cancer cell lines of different origin (8-11,21-25). These sensitizing effects are the result of the Hsp90 inhibitor-mediated abrogation of the $\mathrm{G}_{2}$ checkpoint, apoptosis and the inhibition of DNA repair. These data strongly suggest that targeting Hsp90 with its inhibitors represents a promising strategy for enhancing the sensitivity of cancer cells to radiation.

The first generation of geldanamycin-based Hsp90 inhibitors, including the benzoquinone ansamycins, 17-AAG, 17-DMAG and IPI-504, have been developed and investigated for the treatment of various malignancies (6). Although the geldanamycin derivatives have shown significant antitumor activity against a spectrum of cancers in pre-clinical studies, early clinical results with these Hsp90 inhibitors revealed dose-limiting delayed hepatotoxicity (26), which prompted the discovery of novel non-ansamycin Hsp90 inhibitors with less toxicity. Thus, Chiosis et al designed Hsp90 inhibitors using purine as a scaffold $(27,28)$. PU-H71 is the most potent compound in its class (29), and has shown activity in triple-negative breast cancer (15) and diffuse large-cell lymphoma (16). In addition, Breinig et al, following in vivo hepatocellular carcinoma xenograft mouse model experiments, demonstrated that PU-H71 was retained in tumors at pharmacologically relevant concentrations, while being rapidly cleared from nontumorous liver. Thus, PU-H71 was effective in the treatment of hepatocellular carcinoma, and was well tolerated, indicating a lack of significant hepatotoxicity (17). Collectively, these data indicate that the non-quinone Hsp90 inhibitor, PU-H71, may be a promising anticancer agent.

In this study, we examined the radiosensitizing effects of PU-H71 on human lung cancer cells and observed that, similar to 17-AAG and 17-DMAG, PU-H71 had synergistic effects with radiation. Certain studies have demonstrated that the radiosensitizing effects of Hsp90 inhibitors are mediated by the inhibition of DSB repair $(25,30)$. In our study, we demonstrated that PU-H71 inhibited the repair of DSBs and sensitized human lung cancer cell lines to radiation (Fig. 3). PU-H71 reduced the protein levels of Rad51 and inhibited Rad51 foci formation following X-irradiation. Rad51 is a key component of the HR, an evolutionarily conserved machinery for DSB repair. Previously, we reported that 17-AAG, one of the first 
generation of geldanamycin-based Hsp90 inhibitors, exerts a marked inhibitory effect on the HR process (11). Thus, PU-H71 sensitizes human cancer cells to radiation in a manner similar to that of 17-AAG.

In conclusion, our data demonstrate that PU-H71 inhibits the repair of radiation-induced DSBs by affecting the HR pathway, and potentially sensitizes human lung cancer cells to radiation. By contrast, PU-H71 had only slight radiosensitizing effects on normal human fibroblasts. The combination of PU-H71 and radiotherapy may be a promising therapeutic strategy for certain radioresistant solid tumors.

\section{Acknowledgements}

We thank Dr Y. Matsumoto and Ms. Huizi Li (National Institute of Radiological Sciences, Chiba, Japan) for their providing valuable comments on our manuscript. This study was supported, in part, by Grants-in-Aid for Scientific Research (no. 23591846) from the Japan Society for the Promotion of Science.

\section{References}

1. Ritossa F: Discovery of the heat shock response. Cell Stress Chaperones 1: 97-98, 1996.

2. Westerheide SD and Morimoto RI: Heat shock response modulators as therapeutic tools for the diseases of protein conformation. J Biol Chem 280: 33097-33100, 2005.

3. Wiech H, Buchner J, Zimmerman R and Jakob U: Hsp90 chaperones protein folding in vitro. Nature 358: 169-170, 1992.

4. Schneider C, Sepp-Lorenzino I, Nimmersgern E, Ouerfelli O, Danishefsky S, Rosen N and Harti FU: Pharmacologic shifting of a balance between protein refolding and degradation mediated by Hsp90. Proc. Natl Acad Sci USA 93: 14536-14541, 1996.

5. Zhao R, Davey M, Hsu Y, Kaplanek P, Tong A, Parsons AB, Krogan N, Cagney G, Mal D, Greenblatt J, Boone C, Emili A and Houry WA: Navigating the chaperone network: an integrative map of physical and genetic interactions mediated by the hsp90 chaperone. Cell 120: 715-727, 2005.

6. Neckers L: Hsp90 inhibitors as novel cancer chemotherapeutic agents. Trends Mol Med 8 (suppl 4): S55-S61, 2002.

7. Russell JS, Burgan WE, Oswald KA, Camphausen K and Tofilon PJ: Enhanced cell killing induced by the combination of radiation and the heat shock protein 90 inhibitor 17-allylamino-17-demethoxygeldanamycin: a multitarget approach to radiosensitization. Clin Cancer Res 37: 3749-3755, 2003.

8. MachidaH, Matsumoto Y, Shirai M and Kubota N: Geldanamycin, an inhibitor of Hsp90, sensitizes human tumor cells to radiation. Int J Radiat Biol 79: 973-980, 2003.

9. Machida H, Nakajima S, Shikano N, Nishio J, Okada S, Asayama M, Shirai M and Kubota N: Heat shock protein 90 inhibitor 17-allylamino-17-demethoxygeldamamycin potentiates the radiation response of tumor cells grown as monolayer cultures and spheroids by inducing apoptosis. Cancer Sci 96: 911-917, 2005.

10. Matsumoto Y, Machida $\mathrm{H}$ and Kubota N: Preferential sensitization of tumor cells to radiation by heat shock protein 90 inhibitor geldanamycin. J Radiat Res 46: 215-221, 2005.

11. Noguchi M, Yu D, Hirayama R, Ninomiya Y, Sekine E, Kubota N, Ando K and Okayasu R: Inhibition of homologous recombination repair in irradiated tumor cells pretreated with Hsp90 inhibitor 17-allylamino-17-demethoxygeldamamycin. Biochem Biophys Res Commun 351: 658-663, 2006.

12. Solit DB, Ivy SP, Kopil C, Sikorski R, Morris MJ, SF, Slovin SF, Kelly WK, DeLaCruz A, Curley T, Heller G, Larson S, Schwartz L, Egorin MJ, Rosen N and Scher HI: Phase I trial of 17-allylamino-17-demethoxygeldanamycin in patients with advanced cancer. Clin Cancer Res 13: 1775-1782, 2007.
13. Taldone T, Gozman Maharaj R and Chiosis G: Targeting Hsp90: small-molecule inhibitors and their clinical development. Curr Opin Pharmacol 8: 370-374, 2008.

14. Chiosis G, Kang Y and Sun W: Discovery and development of purine-scaffold Hsp90 inhibitors. Expert Opin Drug Discov 3: 99-114, 2008.

15. Caldas-Lopes E, Cerchietti L, Ahn JH, Clement CC, Robles AI, Rodina A, Moulick K, Taldone T, Gozman A, Guo Y, Wu N, de Stanchina E, White J, Gross SS, Ma Y, Varticovski L, Melnick A and Chiosis G: Hsp90 inhibitor PU-H71, a multimodal inhibitor of malignancy, induces complete responses in triplenegative breast cancer models. Proc Natl Acad Sci USA 106: 8368-8373, 2009.

16. Briones J: Targeted therapy of BCL6-dependent diffuse large B-cell lymphoma by heat-shock protein 90 inhibition. Expert Rev Hematol 3: 157-159, 2010.

17. Breinig M, Caldas-Lopes E, Goeppert B, Malz M, Rieker R, Bergmann F, Schirmacher P, Mayer M, Chiosis G and Kern MA: Targeting heat shock protein 90 with non-quinone inhibitors: a novel chemotherapeutic approach in human hepatocellular carcinoma. Hepatology 50: 102-112, 2009.

18. Li X and Heyer WD: Homologous recombination in DNA repair and DNA damage tolerance. Cell Res 18: 99-113, 2008.

19. Kuribayashi T, Ohara M, Sora S and Kubota N: Scriptaid, a novel histone deacetylase inhibitor, enhances the response of human tumor cells to radiation. Int J Mol Med 25: 25-29, 2010.

20. Bee L, Fabris S, Cherubini R, Mognato M and Celotti L: The efficiency of homologous recombination and non-homologous end joining systems in repairing double-strand breaks during cell cycle progression. PloS One 8: e69061, 2013.

21. Bull EE, Dote H, Brady KJ, Burgan WE, Carter DJ, Cerra MA, Oswald KA, Hollingshead MG, Camphausen K and Tofilon PJ: Enhanced tumor cell radiosensitivity and abrogation of G2 and S phase arrest by the Hsp90 inhibitor 17-(dimethylaminoethylamino)17-demethoxygeldanamycin. Clin Cancer Res 10: 8077-8084, 2004.

22. Bisht KS, Bradbury CM, Mattson D, Kaushal A, Sowers A, Markovina S, Ortiz KL, Sieck LK, Isaacs JS, Brechbiel MW, Mitchell JB, Neckers LM and Gius D: Geldanamycin and 17-allylamino-17-demethoxygeldanamycin potentiate the in vitro and in vivo radiation response of cervical tumor cells via the heat shock protein 90-mediated intracellular signaling and cytotoxicity. Cancer Res 63: 8984-8995, 2003.

23. Koll TT, Feis SS, Wright MH, Teniola MM, Richardson MM, Robles AI, Bradsher J, Capala J and Varticovski L: HSP90 inhibitor, DMAG, synergizes with radiation of lung cancer cells by interfering with base excision and ATM-mediated DNA repair. Mol Cancer Ther 7: 1985-1992, 2008.

24. Stingl L, Stühmer T, Chatterjee M, Jensen MR, Flentje M and Djuzenova CS: Novel HSP90 inhibitors, NVP-AUY922 and NVP-BEP800, radiosensitise tumour cells through cell-cycle impairment, increased DNA damage and repair protraction. Br J Cancer 102: 1578-1591, 2010.

25. Kubota $\mathrm{N}$ and Matsumoto Y: Hsp90 inhibitors are promising radiosensitizers for radiotherapy. Thermal Med 28: 53-62, 2012.

26. Sharp S and Workman P: Inhibitors of the HSP 90 molecular chaperone: current status. Adv Cancer Res 95: 323-348, 2006.

27. Chiosis G, Timaul MN, Lucas B, Munster PN, Zheng FF, Sepp-Lorenzino L and Rosen N: A small molecule designed to bind to the adenine nucleotide pocket of Hsp90 causes Her2 degradation and the growth arrest and differentiation of breast cancer cells. Chem Biol 8: 289-299, 2001.

28. Chiosis G: Discovery and development of purine-scaffold Hsp90 inhibitors. Curr Top Med Chem 6: 1183-1191, 2006.

29. Chiosis G, Rodina A and Moulick K: Emerging Hsp90 inhibitors: from discovery to clinic. Anticancer Agents Med Chem 6: $1-8,2006$.

30. Zaidi S, McLaughlin M, Bhide SA, Eccles SA, Workman P, Nutting CM, Huddart RA and Harrington KJ: The HSP90 inhibitor NVP-AUY922 radiosensitizes by abrogation of homologous recombination resulting in mitotic entry with unresolved DNA damage. PLos One 7: e35436, 2012. 